\title{
The frequency and impact of admission hyperglycemia on short term outcome of acute stroke patients admitted to Tikur Anbessa Specialized hospital, Addis Ababa, Ethiopia: a cross-sectional study
}

\author{
Yared Zenebe Zewde ${ }^{1 *}$ D, Abenet Tafesse Mengesha', Yeweynhareg Feleke Gebreyes ${ }^{2}$ and Halvor Naess ${ }^{3}$
}

\begin{abstract}
Background: Admission hyperglycemia ( $\mathrm{HG}$ ) has been associated with worse outcomes among acute stroke patients. A better understanding and awareness of the potentially adverse influence of hyperglycemia on the clinical outcome of acute stroke patients would help to provide guidance for acute stroke management and prevention of its adverse outcomes. We aimed to assess the frequency of admission hyperglycemia and its impact on short term (30-days) morbidity and mortality outcomes of stroke in adult Ethiopian patients in an urban setting.

Methods: A prospective, cross-sectional study was conducted among acute stroke patients admitted to Tikur Anbessa Specialized Hospital (TASH), within $72 \mathrm{~h}$ of symptom onset, from July to December 2016. Socio-demographic data, neuroimaging findings and capillary blood glucose values were obtained on admission. Hyperglycemia was defined as $>140 \mathrm{mg} / \mathrm{dl}$. National Institute of Health Stroke Scale (NIHSS) and modified Rankin Scale (mRS) were used to assess the baseline stroke severity and the 30-days post-stroke outcome, respectively.

Results: A total of 103 first-ever acute stroke patients were included (mean age $=55.5 \pm 15.3$ years, $64.1 \%$ male and $65 \%$ under the age of 65 years) and 51 (49.5\%) were hyperglycemic at time of admission. The median admission NIHSS score was worse in the hyperglycemic patients 14 (IQR 10-19) compared to normoglycemic patients 11 (IQR 8-15). Among stroke survivors, patients with hyperglycemia were 3.83 times $(95 \% \mathrm{Cl}, 1.99-6.19)$ more likely to be functionally impaired (mRS $=3-5)$ at 30-days compared to normoglycemic patients ( $P=0.041)$.Older age ( $\geq 65$ years) $(P=0.017)$ and stroke severity (NIHSS > 14) $(P=0.006)$ at admission were both significantly associated with poor functional recovery at 30-day. Among patients who died at 30-day, two-third (66.7\%) were hyperglycemic but they failed to show any significant association.

Conclusions: Hyperglycemia is prevalent among Ethiopian stroke patients at the time of presentation and it is associated with significantly poor functional recovery at $30^{\text {th }}$-day of follow up. This finding provides a rationale for achieving normal blood glucose in the course of acute stroke management which could have a favorable impact on the neurological outcome and quality of life for patients.
\end{abstract}

Keywords: Hyperglycemia, Stroke severity, Functional outcome, Mortality, Africa

\footnotetext{
*Correspondence: yaredzene121@gmail.com; yared.zenebe@aau.edu.et

'Department of Neurology, College of Health Sciences, Addis Ababa

University, P.O.Box: 41690, Addis Ababa, Ethiopia

Full list of author information is available at the end of the article
}

(c) The Author(s). 2019 Open Access This article is distributed under the terms of the Creative Commons Attribution 4.0 International License (http://creativecommons.org/licenses/by/4.0/), which permits unrestricted use, distribution, and

reproduction in any medium, provided you give appropriate credit to the original author(s) and the source, provide a link to the Creative Commons license, and indicate if changes were made. The Creative Commons Public Domain Dedication waiver (http://creativecommons.org/publicdomain/zero/1.0/) applies to the data made available in this article, unless otherwise stated. 


\section{Background}

Stroke remains a major global health problem, ranking the second most common cause of death and the third cause of disability worldwide [1]. Report from the 2013 Global Burden of Disease study showed that the absolute numbers of people affected by stroke every year, and lived with the consequence of stroke or died from their stroke, had increased significantly between 1990 and 2013 around the world. In 2013 globally there were 25.7 million stroke survivors, 6.5 million deaths from stroke, 113 million disability-adjusted life years (DALYs) due to stroke and 10.3 million new strokes. It was also found that the prevalence for both ischemic and hemorrhagic stroke nearly doubled across the globe over this period [2].

Although stroke related death and DALY rates have declined in both developed and developing countries over the past several decades, there is a significant increase in the absolute numbers of stroke deaths among younger adults aged between 20 and 64 years in developing countries, where the preponderance of the burden of stroke continued to reside and contributing $75.2 \%$ of deaths from stroke and $81.0 \%$ of stroke-related DALYs $[1,2]$.

In the past few years, developing countries including Sub-Saharan Africa (SSA) are exhibiting rapid urbanization and epidemiological transition with a sharp rise in the population number and life expectancy as well as changing lifestyle and a dietary habit which will increase the risk of cardiovascular disease, particularly stroke [3]. This changes in combination with poor health care service and lack of government commitment will contribute to a looming epidemic of stroke in the SSA regions.

Stroke patient's outcome is influenced by a myriad of factors, including stroke subtype, stroke severity, associated comorbidities (prior history of diabetes mellitus (DM) or hypertension), post-stroke complications, and availability of acute stroke care facilities [4]. Admission hyperglycemia $(\mathrm{HG})$ is one of the potentially modifiable factors associated with adverse stroke outcomes [5]. Several clinical and experimental studies have shown that admission hyperglycemia has a deleterious effect on short term outcomes of acute stroke patients, although some other studies have presented conflicting data [6, 7]. Elevated blood glucose during the acute phase of stroke is not always due to underlying diabetes mellitus and may be due to a stress-induced high cortisol response. However, the notion of causality from hyperglycemia or a consequence of more severe stroke remains controversial $[6,8]$.

There is a higher percentage of in-hospital case fatality and severe neurologic deficits among acute stroke patients admitted to tertiary care hospitals in Ethiopia as compared to the global average [9]. Little is known, however, about the relationship between admission hyperglycemia and stroke outcomes in SSA, particularly in the east Africa countries, where the number of neurologists is limited and access to stroke centers is negligible. So far there is no published data that has assessed the deleterious effect of high blood glucose on stroke patients' outcomes in the region. The aim of this first prospective study among Ethiopian stroke patients was to assess the point-prevalence of admission hyperglycemia and its impact on short term neurological recovery and case fatality. We hypothesized that a high frequency of admission hyperglycemia and less favorable functional recovery with increased mortality rate would be seen in a cohort of Ethiopian stroke patients at thirty-days of follow up.

\section{Methods}

Study design

An institution based prospective, cross-sectional study was conducted at Tikur Anbessa Specialized Hospital (TASH) between July and December, 2016.

\section{Study setting}

TASH is located in Addis Ababa, the capital of Ethiopia. It is the largest and the first tertiary level referral university teaching hospital with an estimated bed capacity of over 700. It has an emergency unit, an intensive care unit, a neurology ward, a clinical laboratory, and a radiology department with a Computerize Tomography (CT) and Magnetic Resonance Imaging (MRI) services. There is an integrated clinical service composed of highly trained neuro-radiologists, neurologists and emergency care physicians who serve for the entire nation.

\section{Study population}

The study population was all patients presenting to the emergency department with neurologic deficits suggestive of acute stroke and who fulfilled the inclusion criteria of age greater than 14 years, presentation within $72 \mathrm{~h}$ of symptom onset, and confirmation of stroke diagnosis using emergency brain CT scan. A non-fasting capillary blood sample was used to estimate the admission blood glucose (BG) using a calibrated glucometer. Exclusion criteria were: age less than 14 years, patients with clinical course consistent with transient ischemic attack (TIA), trauma related cerebral hemorrhage, subarachnoid hemorrhage, prior neurologic deficit, prior stroke, unknown duration from symptom onset and who declined to give consent.

\section{Sample size and sampling technique}

The sample size was calculated using the single population proportion formula $\mathrm{n}=\mathrm{Z} \alpha^{2 *} \mathrm{pq} / \mathrm{d}^{2}=164$ with estimated population proportion of $30 \%$ [10], $\alpha=5 \%$ and $\mathrm{d}=5 \%$. During the study period, all first-ever acute 
stroke patients who met the inclusion criteria were enrolled consecutively.

\section{Baseline data collection}

The socio-demographic and clinical data were collected using a structured questionnaire that was pre-tested in 8 acute stroke patients having weakness on the nondominant side and we got a complete response. We attempted to mitigate selection bias by randomizing participant selection using the same inclusion criteria detailed above. The National Institute of Health Stroke Scale (NIHSS) was used to measure the stroke severity. NIHSS is a 15-item neurologic examination stroke scale that sums the scores from individual elements to provide an overall stroke impairment score. It is a well-validated and commonly used assessment tool to evaluate the baseline neurologic deficit in acute stroke patients. The NIHSS score was dichotomized into: mild stroke (NIHSS score $\leq$ 14) and severe stroke (NIHSS score $>14$ ) [11].

In all patients, BG was documented and hyperglycemia was defined as BG level $\geq 140 \mathrm{mg} / \mathrm{dl}$ and normoglycemia as $B G<140 \mathrm{mg} / \mathrm{dl}$ [12]. DM was diagnosed if the patient had a pre-existing diagnosis of DM or was taking antidiabetics drugs before stroke onset. If the BG was $>200$ $\mathrm{mg} / \mathrm{dl}$ and a repeat Fasting blood glucose (FBG) test showed $\geq 126 \mathrm{mg} / \mathrm{dl}$, then patients were classified as newly diagnosed DM based on ADA diagnostic criteria [13].

\section{Thirty-day outcome}

The modified Rankin Scale (mRS) was used for the assessment of functional outcome at 30-day after the index stroke onset, which may coincide with the time of hospital discharge and for those who were discharged earlier, we followed them by telephone using standardized interview protocol. The $\mathrm{mRS}$ is six-point ordinal scale ranging from 0 (no symptoms) to 6 (death) measuring the degree of disability or dependence in everyday life, including instrumental and basic activities of daily living (ADL). The functional mRS scoring was subcategorized into; good outcome (independence in ADL, mRS score $(0-2)$, and poor outcomes (dependence in ADL, mRS score 3-5). A mRS score of 6 signifies a patient death (30-day mortality) [14].

\section{Statistical analysis}

Data were analyzed using the Statistical Package for Social Sciences version 20.0 software package (SPSS Inc., Chicago, IL, USA). Descriptive statistics were summarized using the frequency and proportion table for categorical data and mean (standard deviation) or median (interquartile range) for continuous data. The Pearson's Chi square test were used to compare noncontinuous data. For dichotomous data, multiple logistic regression models were used to determine univariate and multivariate associations between 30-day outcomes and patient related variables including; demographic factors; prior history of DM; type of stroke based on neuroimaging findings; stroke severity by NIHSS and BG category. Adjusted odds ratios with 95\% confidence interval (CI) were estimated. Level of statistical significance was set at $P<0.05$.

\section{Ethics approval and consent to participate}

Ethics approval was obtained from the Institutional Review Board (IRB) of College of Health Science in Addis Ababa University. A written informed consent was obtained from each patient when clinically appropriate. For patients with depressed consciousness or severe aphasia, written consent was obtained from their care takers. For participants aged 14-18 years, an assent form was obtained from their parents or legal guardians. Confidentiality and anonymity of all patient data were kept throughout the study. The study was performed in accordance with the Declaration of Helsinki.

\section{Results}

\section{Socio-demographic characteristics}

We approached 110 first-ever acute stroke patients, of whom 7 were excluded due to incomplete NIHSS data during hospitalization. The remaining 103 stroke patients were included in the final analysis having a mean age \pm SD of $55.5 \pm 15.3$ years at presentation. The majority $(64.1 \%)$ were male and around two-third (65\%) were under the age of 65 years. Among our study participants, 82 (79.6\%) were married and 8 (7.8\%) were single. Thirty-two (31.1\%) patients were farmers by occupation and $41(39.8 \%)$ were illiterates with no formal education. Findings on initial brain CT scan classified stroke subtypes as 52 (50.5\%) cases of ischemic and 51 (49.5\%) hemorrhagic stroke cases. In $8(7.8 \%)$ of the participants the diagnosis of diabetes was known before the stroke onset. While 7 of our patients had a BG $>200 \mathrm{mg} / \mathrm{dl}$ at presentation, three (2.9\%) of them fulfilled the ADA diagnostic criteria [13] for a newly diagnosed DM after the stroke onset. Table 1 summarizes the socio-demographic and clinical characteristics of the participants.

Relationship between admission blood glucose level and clinical characteristics

Almost half (49.5\%) of our study participants were hyperglycaemic at the time of admission with a BG level $\geq 140 \mathrm{mg} / \mathrm{dl}$. The mean $( \pm \mathrm{SD}) \mathrm{BG}$ level in the normoglycemic and hyperglycemic groups were $119.9 \pm 13.0 \mathrm{mg} / \mathrm{dl}$ and $183.2 \pm 34.5 \mathrm{mg} / \mathrm{dl}$, respectively. Admission hyperglycemic was presented in the majority $7 / 8(87.5 \%)$ of diabetic patients and a multiple regression analysis showed that diabetes diagnosed before or after the stroke onset was related to high admission blood 
Table 1 Socio-Demographic and Clinical Characteristics of acute stroke patients admitted to Tikur Anbessa Specialized Hospital in Addis Ababa, Ethiopia

\begin{tabular}{|c|c|c|}
\hline Variables & Number & Percentage (\%) \\
\hline Age (mean $\pm S D)$, years & $55.5 \pm 15.3$ & \\
\hline \multicolumn{3}{|l|}{ Age groups } \\
\hline$<65$ years & 67 & 65.0 \\
\hline$\geq 65$ years & 36 & 35.0 \\
\hline \multicolumn{3}{|l|}{ Gender } \\
\hline Male & 66 & 64.1 \\
\hline Female & 37 & 35.9 \\
\hline \multicolumn{3}{|l|}{ Marital status } \\
\hline Married & 82 & 79.6 \\
\hline Widowed & 13 & 12.6 \\
\hline Single & 8 & 7.8 \\
\hline \multicolumn{3}{|l|}{ Educational status } \\
\hline Illiterate & 41 & 39.8 \\
\hline Elementary school & 39 & 37.8 \\
\hline High school & 13 & 12.6 \\
\hline College and above & 10 & 9.7 \\
\hline \multicolumn{3}{|l|}{ Occupation } \\
\hline Farmer & 32 & 31.1 \\
\hline Merchant & 27 & 26.2 \\
\hline Housewife & 21 & 20.4 \\
\hline Government employee & 15 & 14.5 \\
\hline Retired/Pension & 4 & 3.9 \\
\hline Student & 4 & 3.9 \\
\hline \multicolumn{3}{|l|}{ Type of stroke } \\
\hline Ischemic stroke & 52 & 50.5 \\
\hline Hemorrhagic stroke & 51 & 49.5 \\
\hline \multicolumn{3}{|l|}{ Diabetes mellitus (DM) } \\
\hline No DM diagnosis & 92 & 89.3 \\
\hline Previously diagnosed DM & 8 & 7.8 \\
\hline Newly diagnosed DM & 3 & 2.9 \\
\hline \multicolumn{3}{|l|}{ Admission NIHSS score } \\
\hline $\mathrm{NIHSS} \leq 14$ & 62 & 60.2 \\
\hline $\mathrm{NIHSS}>14$ & 41 & 39.8 \\
\hline \multicolumn{3}{|l|}{ mRS score at $30^{\text {th }}$ day } \\
\hline $\mathrm{mRS}<3$ & 27 & 26.2 \\
\hline$m R S \geq 3$ & 76 & 73.8 \\
\hline
\end{tabular}

glucose level independent of age, sex, stroke subtype and baseline stroke severity $(P=0.023)$.

The median NIHSS score was higher in the hyperglycemic (BG) patients (14 [IQR 10-19]) as compared to the normoglycemic patients (11 [IQR 8-15]). But a multiple regression analysis showed there was no relationship between BG and stroke severity on admission NIHSS independent of age, sex, diagnosis of diabetes and stroke subtype $(P=0.42)$.

Among the study participants, hemorrhagic stroke was significant increased in patients with admission hyperglycemia $(n=33(64.7 \%)$ vs $n=18(35.3 \%) ; P=0.002)$ when compared to those with normal blood glucose level on admission. The association between admission blood glucose and clinical characteristics of the participants are shown in Table 2.

\section{Thirty-day functional recovery and mortality in relation to hyperglycemia and clinical characteristics}

Among our stroke cohorts, the mean mRS score at 30day was $3.6+1.45$. Ninety-one patients $(88.3 \%)$ had survived until 30th-day and majority (70.3\%) of them showed poor functional recovery (mRS 3-5), while 27 (29.7\%) patients had a good functional outcome (mRS $0-2)$. The association between clinical characteristics and 30-day functional outcome among survivors are shown in Table 3.

The functional recovery of stroke survivors at 30-days were compared across the different clinical and laboratory profiles. Accordingly, a multivariate logistic regression analysis showed patients with high blood glucose level at admission were 3.83 times (95\% CI, 1.99-6.19) more likely to be functionally impaired $(\mathrm{mRS}=3-5)$ at $30^{\text {th }}$-day compared to those with normal glucose $(P=$ $0.041)$. The other factors that were significantly associated with poor functional outcome were older age $(\geq 65$ years) at time of stroke onset (OR 5.53; 95\% CI,1.3622.43; $P=0.017)$ and severe stroke (NIHSS $>14)(\mathrm{OR}$ 0.12 ; $95 \% \mathrm{CI}, 0.03-0.54 ; P=0.006)$ at admission.

The 30 -day mortality rate was $11.7 \%$ with a mRS score of 6. Mortality was significantly increased in patients younger than 65 years of age at time of stroke onset $(P=$ $0.04)$ and severe stroke (NIHSS $>14)$ at time of hospitalization $(P=0.004)$. Although $15.7 \%$ of hyperglycemic patients died at 30-day, on multiple logistic regression no significant difference was found from normoglycemic patients $(P=0.94)$, after adjusting for age, sex, stroke type and severity (see Table 4 ).

\section{Discussion}

We performed this prospective cross-sectional study to determine the frequency of hyperglycemia and its effect on the short-term outcome of acute stroke patients in a resource limited setting where there are neither stroke units nor comprehensive rehabilitation centers exist.

The majority of our participants were males with M:F ratio of 1.8:1, and two-third of them were younger than 65 years with the mean age of $55.5 \pm 15.3$ years at presentation. This is similar to previous studies in Ethiopia [15] and other studies in Africa [16, 17]. However, the 
Table 2 Factors associated with development of hyperglycemia at time of admission among acute stroke patients admitted to Tikur Anbessa Specialized Hospital in Addis Ababa, Ethiopia

\begin{tabular}{|c|c|c|c|c|}
\hline Variable & Hyperglycemia $(\mathrm{N}=51),(\%)$ & Normoglycemia $(\mathrm{N}=52)(\%)$ & Adjusted OR $(95 \% \mathrm{Cl})$ & $P$-value \\
\hline \multicolumn{5}{|l|}{ Age } \\
\hline$<65$ years & $32(47.7)$ & $35(52.3)$ & $1.37(0.52-3.62)$ & \multirow[t]{2}{*}{0.53} \\
\hline$\geq 65$ years & $19(52.7)$ & $17(47.3)$ & 1 & \\
\hline \multicolumn{5}{|l|}{ Gender } \\
\hline Male & $33(50.0)$ & $33(50.0)$ & $0.83(0.33-2.06)$ & \multirow[t]{2}{*}{0.68} \\
\hline Female & $18(48.6)$ & $19(51.4)$ & 1 & \\
\hline \multicolumn{5}{|l|}{ Diagnosis of diabetes mellitus } \\
\hline Yes & $7(87.5)$ & $1(12.5)$ & $0.07(0.01-0.69)$ & \multirow[t]{2}{*}{0.023} \\
\hline No & $44(46.3)$ & $51(53.7)$ & 1 & \\
\hline \multicolumn{5}{|l|}{ Type of stroke } \\
\hline Ischemic & $18(34.6)$ & $34(65.4)$ & 1 & \\
\hline Hemorrhagic & $33(64.7)$ & $18(35.3)$ & $4.24(1.67-10.76)$ & 0.002 \\
\hline \multicolumn{5}{|l|}{ Admission NIHSS score } \\
\hline $\mathrm{NIHSS}>14$ & $25(61.0)$ & $16(39.0)$ & $1.53(0.55-4.21)$ & \multirow[t]{5}{*}{0.42} \\
\hline $\mathrm{NIHSS} \leq 14$ & $26(41.9)$ & $36(58.1)$ & 1 & \\
\hline Median admission NIHSS (IQR) & $14(10-19)$ & $11(8-15)$ & & \\
\hline Mean $B G \pm S D(m g / d l)$ & $183.2 \pm 34.5$ & $119.9 \pm 13.0$ & & \\
\hline Mean $\mathrm{mRS} \pm \mathrm{SD}$ & $3.82 \pm 1.34$ & $3.33 \pm 1.52$ & & \\
\hline
\end{tabular}

Table 3 Factors associated with 30th day poor functional outcome among stroke survivors who were admitted to Tikur Anbessa Specialized Hospital in Addis Ababa, Ethiopia

\begin{tabular}{|c|c|c|c|c|}
\hline \multirow[t]{2}{*}{ Variables } & \multicolumn{2}{|c|}{ 30th day functional outcome among survivors $n=91$} & \multirow{2}{*}{$\begin{array}{l}\text { Adjusted OR } \\
(95 \% \mathrm{Cl})\end{array}$} & \multirow[t]{2}{*}{$P$-value } \\
\hline & mRS 0-2 $(n=27,29.7 \%)$ & mRS 3-5 $(n=64,70.3 \%)$ & & \\
\hline \multicolumn{5}{|l|}{ Age } \\
\hline$<65$ years & $22(81.5)$ & $34(60.7)$ & 1 & \\
\hline$\geq 65$ years & $5(14.3)$ & $30(85.7)$ & $5.53(1.36-22.43)$ & 0.017 \\
\hline \multicolumn{5}{|l|}{ Gender } \\
\hline Male & $17(29.3)$ & $41(70.7)$ & $0.99(0.34-2.88)$ & 0.98 \\
\hline Female & $10(30.3)$ & $23(69.7)$ & 1 & \\
\hline \multicolumn{5}{|c|}{ History of diabetes mellitus } \\
\hline Yes & $1(12.5)$ & $7(87.5)$ & $0.29(0.02-3.97)$ & 0.35 \\
\hline No & $26(31.3)$ & $57(68.7)$ & 1 & \\
\hline \multicolumn{5}{|c|}{ Admission Blood glucose level } \\
\hline$\geq 140 \mathrm{mg} / \mathrm{dl}$ & $9(20.9)$ & $34(79.1)$ & $3.83(1.99-6.19)$ & 0.041 \\
\hline$<140 \mathrm{mg} / \mathrm{dl}$ & $18(37.5)$ & $30(62.5)$ & 1 & \\
\hline \multicolumn{5}{|l|}{ Type of stroke } \\
\hline Ischemic & $18(36.0)$ & $32(64.0)$ & $3.52(0.96-12.94)$ & 0.058 \\
\hline Hemorrhagic & $9(21.9)$ & $32(78.1)$ & 1 & \\
\hline \multicolumn{5}{|c|}{ Admission NIHSS score } \\
\hline $\mathrm{NIHSS}>14$ & $3(9.7)$ & $28(90.3)$ & $0.12(0.03-0.54)$ & 0.006 \\
\hline $\mathrm{NIHSS} \leq 14$ & $24(40.0)$ & $36(60.0)$ & & \\
\hline
\end{tabular}


Table 4 Factors associated with 30 -day mortality among stroke patients admitted to Tikur Anbessa Specialized Hospital in Addis Ababa, Ethiopia

\begin{tabular}{|c|c|c|c|c|}
\hline \multirow[t]{2}{*}{ Variables } & \multicolumn{2}{|l|}{ Patients' condition at 30th day } & \multirow{2}{*}{$\begin{array}{l}\text { Adjusted OR } \\
(95 \% \mathrm{Cl})\end{array}$} & \multirow[t]{2}{*}{$P$-value } \\
\hline & Died $(m R S=6) n=12,11.7 \%$ & Alive $(m R S<6) n=91,88.3 \%$ & & \\
\hline \multicolumn{5}{|l|}{ Age } \\
\hline$<65$ years & $11(16.4)$ & $56(83.6)$ & $0.05(0.003-0.83)$ & \multirow[t]{2}{*}{0.04} \\
\hline$\geq 65$ years & $1(2.8)$ & $35(97.2)$ & 1 & \\
\hline \multicolumn{5}{|l|}{ Gender } \\
\hline Male & $8(12.1)$ & $58(87.9)$ & $1.1(0.18-6.89)$ & \multirow[t]{2}{*}{0.92} \\
\hline Female & $4(10.8)$ & $33(89.2)$ & 1 & \\
\hline \multicolumn{5}{|c|}{ Admission Blood glucose level } \\
\hline$\geq 140 \mathrm{mg} / \mathrm{dl}$ & $8(15.7)$ & $43(84.3)$ & $0.96(0.15-6.36)$ & \multirow[t]{2}{*}{0.97} \\
\hline$<140 \mathrm{mg} / \mathrm{dl}$ & $4(7.7)$ & $48(92.3)$ & 1 & \\
\hline \multicolumn{5}{|l|}{ Type of stroke } \\
\hline Ischemic & $2(3.8)$ & $50(96.2)$ & 1 & \\
\hline Hemorrhagic & 10 (19.6) & $41(80.4)$ & $4.62(0.34-63.15)$ & 0.25 \\
\hline \multicolumn{5}{|c|}{ Admission NIHSS score } \\
\hline $\mathrm{NIHSS}>14$ & $10(24.4)$ & $31(75.6)$ & $0.039(0.004-0.38)$ & \multirow[t]{2}{*}{0.004} \\
\hline $\mathrm{NIHSS} \leq 14$ & $2(3.2)$ & $60(96.8)$ & 1 & \\
\hline
\end{tabular}

average age of our stroke patients was younger than stroke victims in western countries. The median age reported by the European Registers of Stroke was 73 years [IQR 62 to 81] [18].

We found an equal proportion of ischemic (50.5\%) and hemorrhagic strokes (49.5\%) with 1.02:1 ratio. However, a higher proportion of ischemic stroke had been reported by other African countries [16, 17] in accordance with the western epidemiology [19]. Our result is similar to prior hospital-based studies in Ethiopia (1.72: 1) [15] and (1.01:1) [20]. The possible explanation for the equal proportion of ischemic and hemorrhagic stroke in our setup may be related to the study setting, where most minor ischemic strokes and TIA's were treated at the primary care centers with spontaneous resolution of clinical symptoms and minor disabilities that did not necessitate referrals to a tertiary care center like ours.

We have shown a high prevalence $(49.5 \%)$ of hyperglycaemia in patients presenting with acute stroke to a hospital. This observation is consistent with several other studies in which the reported prevalence of admission hyperglycemia in acute stroke patients varied from 20 to $50 \%$, depending on the study design (prospective or retrospective), the cut off value for hyperglycemia and stroke subtype $[12,21]$. A $28 \%$ prevalence rate was reported by Ogunrin et al. [22], using the same hyperglycemic definition ( $\geq 140 \mathrm{mg} / \mathrm{dl}$ ) from west Africa, Nigeria. But the authors attributed the lower prevalence to the retrospective design of their study and that might have affected their results, as only 100 of their 163 patients had blood glucose estimated at admission.

Diabetes mellitus is a well-recognized risk factor for stroke and the frequency of diabetes in our study was $10.7 \%$. This finding is slightly higher than the prevalence of DM across different localities of Ethiopia, 0.3 to $7.0 \%$ [23]. We found a $2.9 \%$ prevalence of newly diagnosed diabetes which probably reflect the prevalence of undiagnosed diabetes in acute stroke population at time of hospitalization, although geographical variations noted. A comparable frequency of 5.3\% was reported by Woo J and his colleagues, from a regional general hospital in Hong Kong [24]. While a higher 11\% prevalence was reported by L.S. Williams et al. [25]. A study from USA showed a short median time between the onset of diabetes and stroke and a high incidence of newlydiagnosed diabetes in acute stroke patients could be expected [26]. These findings support the importance of screening all acute stroke patients for undetected diabetes and confirm the diagnosis by determining the fasting plasma glucose or glycated hemoglobin (HbA1c) level, especially if the admission glucose level was very high (> $200 \mathrm{mg} / \mathrm{dl}$ ).

In this study, the median NIHSS score at admission was higher (14) in the hyperglycemic group as compared to (11) normoglycemic group. But on multiple logistic regression, we found no significant difference on stroke severity (NIHSS > 14) between the two groups after adjusting for age, sex, diabetes history and stroke type. In the contrary, Stead and his colleagues reported 
strong association between hyperglycemia and sever stroke at presentation [27].

Our patients with hyperglycemia had a significant disability with poor functional recovery $(\mathrm{mRS} \geq 3)$ at 30-day. This finding is in line with hospital-based report among ischemic stroke patients in China, where hyperglycemia was identified as an independent predictor for a poor functional outcome (defined as $\mathrm{mRS}$ $\geq 3$ ), at 30 and 90 days after the stroke onset [28]. Sun et al. [29] analyzed a large cohort of patients with intracerebral hemorrhage, which showed an elevated admission blood glucose was an independent predictor of 3-month poor outcome and they concluded that hyperglycemia has a greater prognostic value in nondiabetics than diabetics with a similar glucose level. A possible explanation for the negative association between hyperglycemia and poor functional outcomes after a stroke includes direct toxic effect of high blood glucose to ischemic neurons which may disrupt the blood-brain barrier and promote hemorrhagic infarct conversion [28] and also increasing superoxide production may exacerbate perihematomal cell death in the brain [29].

Stroke severity at admission was also significantly associated with poor functional outcome and increased risk of death at 30 days. Green SR et al. [8] compared 103 acute ischemic stroke patients based on their admission blood glucose level and they found a similar association, where functional outcomes at 30- and 90-day were poor among the diabetics and stress hyperglycemic groups who also had a higher NIHSS score of $>13$ at admission These findings possibly explained by the prolonged hospital stay, severe motor weakness and a higher rates of medical complications that follows severe stroke.

Multiple studies [6, 12, 29] showed the relationship between high admission blood glucose and short term mortality among acute stroke patients at different time periods after stroke onset. However, in this study majority $(66.7 \%)$ of the patients died at 30-day were hyperglycemic at admission but they failed to show the expected negative associations. This discrepancy could be explained by the small number of participants and those patients with severer stoke were possibly died before reaching the hospital. Several limitations must be acknowledged. First, the diagnosis of DM was based only on medical. history and FBG test where confirmatory tests like $\mathrm{HbA1c}$ were not done to exclude stress hyperglycemia. Second, a single-center, hospital-based study in an urban setting might introduce. selection bias and likely to overrepresent the more severe stroke cases referred for tertiary care. Therefore, we acknowledge the limited generalizability of our findings to the general population.

\section{Conclusion}

Our analysis showed a higher prevalence of hyperglycemia in Ethiopian acute stroke patients at presentation and it had a significant association with poor functional recovery at short-term. The negative impact of admission hyperglycemia on functional recovery suggests that achieving normal blood glucose in the early stages of stroke may favorably influence the clinical recovery and quality of life of the patients. Further studies with a larger cohort in a multi-center setting are required to determine the independent role of hyperglycemia in neurological outcomes in stroke patients.

\section{Abbreviations \\ ADA: American Diabetes Association; ADL: Activities of daily living; BG: Admission hyperglycemia; CT: Computerized Tomography; \\ DALY's: Disability-adjusted life years; FBG: Fasting blood glucose; GBD: Global Burden of Diseases; HbA1c: glycated hemoglobin; MRI: Magnetic resonance imaging; mRS: modified Rankin Scale; NIHSS: National Institute of Health Stroke Scale; SSA: Sub-Saharan Africa; TIA: Transient Ischemic Attack}

\section{Acknowledgements}

The authors would like to thank all participants and their caregivers for their cooperation to take part in this study. Finally, we would like to appreciate Dr. Jake Mckay, for taking his time in proofreading and correcting the typos, syntax and grammar errors on our final version manuscript.

\section{Authors' contributions}

YZZ in study designing, data acquisition, analysis, interpretation, review and critique. ATM and YFG in analysis, interpretation, review and critique. HN in review and critique. YZZ and ATM also participated in manuscript preparation. All authors read and approved the final manuscript.

\section{Authors' information}

Yared Zenebe Zewde (MD), Assistant professor of neurology

- A consultant neurologist and staff at the department of Neurology, College

of Health Sciences, Addis Ababa University

- Working at Tikur Anbessa Specialized Hospital, under Addis Ababa

University, College of Health Sciences

- Teach clinical neurology and neuroscience for both undergraduate medical students and graduate medical and neurology residents.

- Conducting different research projects in the field of neuroscience and

collaborate with international organizations like WHO in community-based researches in Ethiopia.

- Having special interests in stroke, dementia, headache and epilepsy

-E mail-yaredzene121@gmail.com/yared.zenebe@aau.edu.et

- P.O.Box: 41690, Addis Ababa, Ethiopia.

- Telephone number- + 251-911-983-447/+ 251-922-122-015

\section{Funding}

No funding sources.

\section{Availability of data and materials}

The datasets used and/or analysed during the current study are available from the corresponding author on reasonable request.

\section{Ethics approval and consent to participate}

The study protocol was approved by the Institutional Review Board of College of Health Science in Addis Ababa University. All patients have provided the written informed consent for participation in this study.

Consent for publication

Not Applicable.

Competing interests

The authors declare that they have no competing interests. 


\section{Author details}

'Department of Neurology, College of Health Sciences, Addis Ababa University, P.O.Box: 41690, Addis Ababa, Ethiopia. ${ }^{2}$ Department of Internal Medicine, College of Health Sciences, Addis Ababa University, Addis Ababa, Ethiopia. ${ }^{3}$ Department of Neurology, University of Bergen, Haukeland University Hospital, Bergen, Norway.

Received: 16 July 2019 Accepted: 17 December 2019

Published online: 27 December 2019

\section{References}

1. Feigin VL, Norrving B, Mensah GA. Global Burden of Stroke. Circ Res. 2017; 120:439-48. https://doi.org/10.1161/circresaha.116.308413.

2. Feigin VL, Krishnamurthi RV, Parmar P, Norrving B, Mensah GA, Bennett DA Barker-Collo S, et al. Update on the global burden of ischemic and hemorrhagic stroke in 1990-2013: the GBD 2013 study. Neuroepidemiology. 2015;45(3):161-76. https://doi.org/10.1159/000441085.

3. Seana L. Paul; Velandai K Srikanth; Amanda G Thrift The large and growing burden of stroke: Current Drug Targets, Volume 8, Number 7, 2007, pp. 786-793(8)

4. Barber M, Wright F, Dj S, Langhorne P. Predictors of early neurological deterioration after ischemic stroke: a case-control study. Gerontology. 2004; 50:102-9.

5. Kawai N, Keep RF, Betz AL, Dietrich WD. Hyperglycemia and the vascular effects of cerebral ischemia. Stroke. 1997;28:149-54.

6. Se C, Hunt D, Malmberg K, Pathak P, Hc G. Stress hyperglycaemia and prognosis of stroke in non-diabetic and diabetic patients: a systematic overview. Stroke. 2001;32:2426-32.

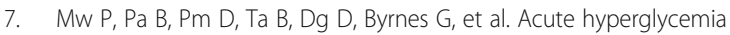
adversely affects stroke outcome: a magnetic resonance imaging and spectroscopy study. Ann Neurol. 2002;52:20-8.

8. Green SR, Lokesh S, Kadavanu TM, Jayasingh K, Ragupathy S. A study of stress hyperglycemia and its relationship with the neurological outcome in patients presenting with acute ischemic stroke. Int J Adv Med. 2016; 3:546-51.

9. Gedefa B, Menna T, Berhe T, Abera H. Assessment of risk factors and treatment outcome of stroke admissions at St. Paul's teaching hospital, Addis Ababa, Ethiopia. J Neurol Neurophysiol. 2017:8:431. https://doi.org/10. 4172/2155-9562.1000431.

10. Adeloye D. An estimate of the incidence and prevalence of stroke in Africa: a systematic review and meta-analysis. PLoS One. 2014:9:e100724.

11. Alvarez-Sabin J, Molina CA, Montaner J, Arenillas JF, Huertas R, Ribo M, Codina A, Quintana M. Effects of admission hyperglycemia on stroke outcome in reperfused tissue plasminogen activator-treated patients. Stroke. 2003;34:1235-41.

12. Godoy DA, Soler C, Videtta W. Hyperglycemia in nondiabetic patients during the acute phase of stroke. Arq Neuropsiquiatr. 2012;70(2):134-9.

13. American Diabetes Association. Diagnosis and classification of diabetes mellitus. Diabetes Care. 2010;33(Suppl 1):S62-9.

14. Eriksson M, Norrving B, Terént A, Stegmayr B. Functional outcome 3 months after stroke predicts long-term survival. Cerebrovasc Dis. 2008;25(5):423-9.

15. Gebremariam SA, Yang HS. Types, risk profiles, and outcomes of stroke patients in a tertiary teaching hospital in northern Ethiopia. eNeurologicalSci. 2016;3:41-7.

16. Jowi JO, Mativo PM. Pathological sub-types, risk factors and outcome of stroke at the Nairobi hospital, Kenya. East Afr Med J. 2008;85(12).

17. Atadzhanov M, Mukomena PN, Lakhi S, Ross OA, Meschia JF. Stroke characteristics and outcomes of adult patients admitted to the university teaching hospital, Lusaka, Zambia. Open Gen Intern Med J. 2012;5:3-8. https://doi.org/10.2174/1874076601205010003.

18. Heuschmann PU, Wiedmann S, Wellwood I, Rudd A, Di Carlo A, Bejot Y, et al. Three-month stroke outcome: the European registers of stroke (EROS). Neurology. 2011;76:159-65.

19. Wolfe CD, Rudd AG, Howard R, Coshall C, Stewart J, Lawrence E, Hajat C, Hillen T. Incidence and case fatality rates of stroke subtypes in a multiethnic population: the South London stroke register. J Neurol Neurosurg Psychiatry. 2002;72(2):211-6.

20. Deresse B, Shaweno D. Epidemiology and in-hospital outcome of stroke in South Ethiopia. J Neurol Sci. 2015;355(1-2):138-42. https://doi.org/10.1016/j. jns.2015.06.001.
21. Scott JF, Robinson GM, O'connell JE, Kgmm A, Gray CS. Prevalence of admission hyperglycaemia across clinical sub-types of stroke. Lancet. 1999: 353:376-7.

22. Ogunrin AO, Unuigbe $E$, Eregie A, Amu E, Isah A, Onunu A. The prognostic value of admission blood glucose levels in Nigerian patients with stroke: a 10-year retrospective analysis. Trop Dr. 2004;34(3):184-5. https://doi.org/10. $1177 / 004947550403400324$.

23. Abebe N, Kebede T, Addise D. Diabetes in Ethiopia 2000-2016 prevalence and related acute and chronic complications; a systematic review. Afr J Diabetes Med. 2017;25(2).

24. Woo J, Lam CWK, Kay R, Wong AHY, Teoh R, Nicholls MG. The influence of hyperglycaemia and diabetes mellitus on immediate and 3-month morbidity and mortality after acute stroke. Arch Neurol. 1990;47:1174-7.

25. Williams LS, Rotich J, Qi R, Fineberg N, Espay A, Bruno A, Se F, Wr T. Effects of admission hyperglycaemia on mortality and costs in acute ischemic stroke. Neurology. 2002;59:67-71.

26. Davis PH, Dambrosia JM, Schoenberg BS, et al. Risk factors for ischemic stroke: a prospective study in Rochester, Minnesota. Ann Neurol. 1987;22: 319-27.

27. Stead LG, Gilmore RM, Bellolio MF, et al. Neurocrit Care. 2009;10:181. https:// doi.org/10.1007/s12028-008-9080-0.

28. Liu L, Zhan L, Wang Y, et al. Metabolic syndrome and the short-term prognosis of acute ischemic stroke: a hospital-based retrospective study. Lipids Health Dis. 2015;14:76.

29. Sun S, Pan Y, Zhao X, et al. Prognostic Value of Admission Blood Glucose in Diabetic and Non-diabetic Patients with Intracerebral Hemorrhage. Sci Rep. 2016;6:32342. https://doi.org/10.1038/srep32342.

\section{Publisher's Note}

Springer Nature remains neutral with regard to jurisdictional claims in published maps and institutional affiliations.

Ready to submit your research? Choose BMC and benefit from:

- fast, convenient online submission

- thorough peer review by experienced researchers in your field

- rapid publication on acceptance

- support for research data, including large and complex data types

- gold Open Access which fosters wider collaboration and increased citations

- maximum visibility for your research: over $100 \mathrm{M}$ website views per year

At $\mathrm{BMC}$, research is always in progress.

Learn more biomedcentral.com/submissions 